\title{
The relationship between knowledge about sexually transmitted diseases and actual sexual behaviour in a group of teenage girls
}

\author{
Agneta Andersson-Ellström, Lars Forssman, Ian Milsom
}

Purpose: To assess longitudinally the relationship between knowledge about sexually transmitted diseases (STDs) and sexual behaviour, contraceptive use, STD protection and social class in a group of Swedish teenage girls.

Methods: Girls starting their upper secondary school education were invited to attend a teenage clinic during a period of 2 years (5 visits). Questions were asked about family situation, sexual activity, contraceptives, STD protection and knowledge about STD. Gynaecological examinations were performed on entry and completion, and when necessary during the observation period.

Results: Eighty-eight girls completed all visits during the observation period. At 16 years of age there were no significant differences in knowledge about various STD and STD protection between girls from different social classes or with respect to coital experience, age of coitarche and the subsequent number of sexual partners at 18 years of age. At 18 years of age there was a better knowledge about STDs and the need for STD protection $(\mathrm{p}<0.01)$ among girls with coital experience compared with those who had no coital experience. Girls reporting many lifetime partners were best informed, but in spite of solid knowledge they did not protect themselves from infection. Even though $34 \%$ of the girls with coital experience were found to harbour a STD during the course of this study, almost all girls denied the possibility of having acquired or transmitted an infection.

Conclusions: Although girls were well-informed about sexually transmitted diseases and knew how to avoid infections this knowledge had little influence on behaviour.

(Genitourin Med 1996;72:32-36)

Keywords: sexually transmitted diseases; knowledge and attitudes; contraceptive use; adolescent; sexual behaviour

Centre for Public

Health Research and the Gripen District Health Care Centre, Karlstad, Sweden and the Department of Obstetrics and Gynecology, University of Gothenburg, East Hospital, Gothenburg, Sweden

A Andersson-Ellström L Forssman

I Milsom

Address correspondence to: Agneta Andersson-Ellstrom, Gyn mottagningen, VC Gripen, Box 547, S-651 12 Karlstad, Sweden.

Accepted for publication 6 November 1995

\section{Introduction}

Reproductive health is due in part to behavioural factors. An early sexual debut increases the risks for sexually transmitted diseases (STDs) and their consequences, and also predisposes for continued risk behaviour. ${ }^{1-4}$ Numerous partners and inadequate contraception increase the risk of unwanted pregnancy as well as STD. One consequence of chlamydial infection is infertility ${ }^{15}$ while human papilloma virus infection (HPV) may lead to premalignant cervical changes. ${ }^{6}$ Adequate behaviour in relation to these risks requires knowledge.

Studies about sex-related risks have shown that knowledge has improved in the last decade $^{7-10}$ but there are concerns that behaviour has not changed accordingly. ${ }^{11}$ Adolescents are those most in danger as they are in a psychological developing process, and feelings of invulnerability and denial of risks influence their behaviour. ${ }^{12-14}$ It is particularly important in adolescents that the inconvenience of adopting new behaviours is balanced by the awareness of perceived risks. ${ }^{12} 15$

The aim of this study was to longitudinally assess the level of knowledge about STDs and STD protection in a group of Swedish girls between the ages of 16 and 18 years, and to determine if the level of knowledge about STD correlates with sexual behaviour, contraceptive use and social class.

\section{Materials and methods}

In Karlstad, a middle-sized Swedish city, between September 1989 and September 1990 , all girls $<18$ years commencing their upper secondary school education in the health care programme course were invited to participate in a study about sexuality and sexually transmitted diseases. Participation in the study involved two years of gynaecological health control care and the possibility of contraceptive advice. Informed consent was obtained from each subject and the study was approved by the Ethics Committee, Örebro.

Those who agreed to participate were called to the Teenage Clinic every six months for a structured face-to-face interview about their situation and about their sexual, contraceptive and STD-protective behaviour by one of the investigators (AA-E). A total of five visits were made. At the first and last visit the girls answered a standardised, self-administered questionnaire about family situation, sexuality, knowledge and attitudes to contraceptives and sexually transmitted diseases (STDs). A gynaecological examination for detection of clinical manifestations of infection, such as genital warts, and including a chlamydia test, cervix cytology and samples for human papilloma virus deoxy ribonucleic acid, HPVDNA, measured by polymerase chain reaction (PCR) was performed at these two visits. Chlamydia tests were also taken during the 
Table 1 Family background and sexual experience in the girls when aged 18 years, according to socio-economic group. Distribution between groups was compared with the chi square test. Comparisons of mean values between groups were performed using Duncan's multiple range test

\begin{tabular}{|c|c|c|c|c|c|}
\hline & \multicolumn{3}{|c|}{ Socio-economic group } & \multirow[b]{2}{*}{$\begin{array}{l}\text { Total } \\
n=88 \\
n(\%)\end{array}$} & \multirow[b]{2}{*}{$\begin{array}{l}\text { Significance } \\
\text { of difference }\end{array}$} \\
\hline & $\begin{array}{l}1 \\
n=13 \\
n(\%)\end{array}$ & $\begin{array}{l}2 \\
n=45 \\
n(\%)\end{array}$ & $\begin{array}{l}3 \\
n=41 \\
n(\%)\end{array}$ & & \\
\hline \multirow{8}{*}{$\begin{array}{l}\text { Divorced parents } \\
\text { Living with one or } \\
\text { both parents } \\
\text { Living alone } \\
\text { Living with partner } \\
\text { Steady boy friend } \\
\text { Coital debut before study } \\
\text { No coital debut at } \\
\text { end of study }\end{array}$} & $3(23)$ & $7(21)$ & $10(24)$ & $20(23)$ & NS \\
\hline & & & & & \\
\hline & $\begin{array}{l}7(54) \\
4(31)\end{array}$ & $\begin{array}{r}21(62) \\
8(24)\end{array}$ & $\begin{array}{r}25(61) \\
9(22)\end{array}$ & $\begin{array}{l}53(61) \\
21(24)\end{array}$ & $\begin{array}{l}\text { NS } \\
\text { NS }\end{array}$ \\
\hline & $2(15)$ & $5(15)$ & $9(22)$ & $\begin{array}{l}21(24) \\
16(18)\end{array}$ & NS \\
\hline & $7(54)$ & $21(62)$ & $29(71)$ & $57(65)$ & NS \\
\hline & $6(46)$ & $22(65)$ & $25(61)$ & $53(60)$ & NS \\
\hline & $4(31)$ & $7(21)$ & $6(15)$ & $17(19)$ & NS \\
\hline & & $1(3)$ & $4(10)$ & $5(6)$ & NS \\
\hline History of STD* & $1(8)$ & $5(15)$ & $5(12)$ & $11(13)$ & NS \\
\hline \multirow[t]{2}{*}{ Age at first coitus } & & & & & \\
\hline & $15 \cdot 6(1 \cdot 6)$ & $15 \cdot 1(1 \cdot 2)$ & $15 \cdot 5(1 \cdot 3)$ & $15 \cdot 4(1 \cdot 3)$ & NS \\
\hline $\begin{array}{l}\text { Number of coitus } \\
\text { partners (mean, (SD)) }\end{array}$ & $4 \cdot 6(2.9)$ & $3.8(4.9)$ & $3 \cdot 7(2 \cdot 1)$ & $3.9(2.9)$ & NS \\
\hline
\end{tabular}

${ }^{\star}$ Chlamydia and/or genital warts.

study when indicated. We distinguished between a coitus partner with whom the girl has penetrating sex and a boy-friend with whom the girl, according to her own definition is "going steady" without necessarily having coitus.

An assessment of the girls knowledge about STDs and STD protection was performed at 16 and 18 years of age. The girls were asked relevant practical questions regarding how one avoids and identifies STD, forms of treatment and consequences of STD (chlamydia, 8 questions, condyloma 4 questions, gonorrhoea 3 questions, genital herpes 1 multiple choice question). In order to be able to compare the level of knowledge between different STDs and to follow changes in knowledge with time the number of correct answers to questions for each infection was graded from 0 or 1 .

The sample was divided into three socioeconomic groups according to the classification made by the National Bureau of Statistics, Sweden. ${ }^{16}$ The girls were classified according to the occupation of the father except in seven cases where the mother had a higher educational level, and in two cases where the girls related only to their mothers. Group 1 consisted of employed and selfemployed professionals, higher civil servants and executives. Group 2 of intermediate nonmanual employees and self-employed other than professionals and group 3 of manual workers and assistant non-manual employees (table 1).

\section{Statistical methods}

Comparison of mean values between 2 groups was performed using Students $t$ test. Distribution between groups was compared with Fishers's exact test. Duncan's multiple

Table 2 Difference in level of knowledge about sexually transmitted diseases (mean, $(S D))$ in the same women $(n=88)$ between 16 and 18 years of age

\begin{tabular}{lllll}
\hline & 16 years & 18 years & Difference & $\begin{array}{l}\text { Significance } \\
\text { of difference }\end{array}$ \\
\hline Chlamydia & $0.37(0.15)$ & $0.46(0.15)$ & $0.08(0.17)$ & $\mathrm{p}<0.001$ \\
Condyloma & $0.26(0.25)$ & $0.41(0.23)$ & $0.14(0.28)$ & $\mathrm{p}<0.001$ \\
Gonorrhoea & $0.27(0.16)$ & $0.33(0.20)$ & $0.06(0.23)$ & $\mathrm{p}<0.01$ \\
Herpes & $0.03(0.18)$ & $0.03(0.18)$ & $0.00(0)$ & $\mathrm{NS}$ \\
\hline
\end{tabular}

range test was used to compare mean values between 3 or more groups simultaneously.

\section{Results}

One hundred and sixty-eight girls started their upper secondary school education in the health care programme course during the study period and were invited to participate in the study. Ninety-eight girls (58\%) accepted the invitation to participate and 89 completed the study, but complete data were available for only 88 . When entering the study the girls were between 15 and 17 years old (mean age $16 \cdot 1$ years). There were no significant differences between the nine girls who dropped out of the study and the girls who completed the study with respect to age, socioeconomic background, age of coitarche, number of coitus partners and use of contraceptives. A description of the family background and sexual experience of the 88 girls, showing no differences between the girls according to socioeconomic class is shown in table 1.

At the age of 16 years 53 of the 88 girls $(60 \%)$ reported coital experience. The corresponding figure at 18 years of age was 71 girls $(81 \%)$. Seven of 17 girls not yet having had their first coitus at 18 years of age reported experience of petting. Seven of the 71 girls with coitus experience at 18 years of age reported the same steady partner during the 2 year follow-up period.

\section{Knowledge about STD}

There were no significant differences in knowledge about various STDs and STD protection between girls from different social classes or with respect to coital experience. There was, however, a tendency to a higher level of knowledge among girls with more sexual experience, an earlier age of coitarche or a higher number of coital partners. At 18 years of age there was a higher level of knowledge regarding STDs and STD protection ( $p<$ 0.01 ) among girls with coital experience compared with those who had no coital experience.

Differences in the level of knowledge between the various STDs at 16 and 18 years of age are shown in table 2 . The girls had the highest level of knowledge regarding chlamydia. Knowledge regarding condyloma and gonorrhoea were similar at 16 years of age, both being lower $(p<0.001)$ than for chlamydia. The girls had least knowledge about genital herpes at both 16 and 18 years of age. There was an improvement in knowledge regarding chlamydia $(p<0.001)$, condyloma $(\mathrm{p}<0.001)$ and gonorrhoea $(\mathrm{p}<0.01)$ between 16 and 18 years of age (table 2). During the same period there was no increase in knowledge regarding genital herpes.

Nearly half of the girls $(47 \%)$ considered themselves insufficiently informed about STDs, especially about symptoms and consequences, the corresponding figures for insufficient knowledge regarding birth control methods, and pregnancy and abortion were $10 \%$ and $18 \%$ respectively. Almost everyone 
Table 3 Contraceptive method related to partner change among those reporting coitus last month at 18 years of age

\begin{tabular}{lcc}
\hline & \multicolumn{2}{l}{ Partner change last 6 months } \\
\cline { 2 - 3 } Contraceptive method & $\begin{array}{l}\text { No, } n=31 \\
n(\%)\end{array}$ & $\begin{array}{l}\text { Yes, } n=22 \\
n(\%)\end{array}$ \\
\hline $\begin{array}{l}\text { Condom alone or with oral } \\
\text { contraceptive }\end{array}$ & $4(13)$ & $3(14)$ \\
Oral contraceptive alone & $25(81)$ & $12(55)$ \\
No contraception & $2(6)$ & $7(32)$ \\
\hline
\end{tabular}

Comparison between groups with Fisher's exact test, significance of difference indicated by ${ }^{\star}=p$ $<0.05$ when appropriate. had heard about sexually transmitted infections in school. Most girls emphasised individual reading as the best source of information and a friend as the most common person for a discussion about contraception, abortion and sexually transmitted diseases. The sources of information or partners for discussion were as follows: newspapers $93 \%$, friends $91 \%$, boyfriend $84 \%$, parents $41 \%$, other adult $53 \%$. All girls proposed condoms as the best way to avoid STDs.

\section{Sexual behaviour and contraception}

Unprotected coitus was more frequent ( $\mathrm{p}<$ 0.05 ) while the use of a condom was no more common in connection with recent partner change (table 3). Neither was frequent partner change related to reliable STD protection. Twenty girls reported more than 4 life-time partners at the age of 18 and had changed partners on average 4.3 times (range 1-20) during the study. Nineteen of them reported coitus without condom in relationships of less than 6 months duration. Most girls were convinced they had neither acquired (96\%) nor transmitted (93\%) an infection at their latest coitus. Only one girl feared that she had been at risk of catching an STD at her latest coitus and one thought she might have given her partner an infection. During the course of this study 11 girls reported having had an STD (table 1). There was a tendency to increased condom use among those with a history of STD, but the difference was not statistically significant. As a result of our investigations, 24 of the girls were actually found to harbour an STD during the study. Eighteen girls were found to have HPV-DNA in the cervix during the study period (analysed at a later date), 4 girls had a chlamydia infection and 2 girls had both infections). Thus, during the course of this study, STD was objectively diagnosed in $34 \%$ of the girls who had had their sexual debut.

Contraceptive use during the last month before the first and last visit is shown in the figure. At the last visit 66 girls (93\%) reported experience of oral contraceptives (OC). Experience of condom use was reported by 63 (89\%), of whom $45(71 \%)$ had adopted this method sometime during the last year. All girls with experience of condoms mentioned protection against pregnancy as the reason for employing this method. Only 35 (56\%) mentioned STD protection as a contributing reason for condom use. Fifty-eight girls (92\%) reported consistent condom use during the whole period of study. The number of coital

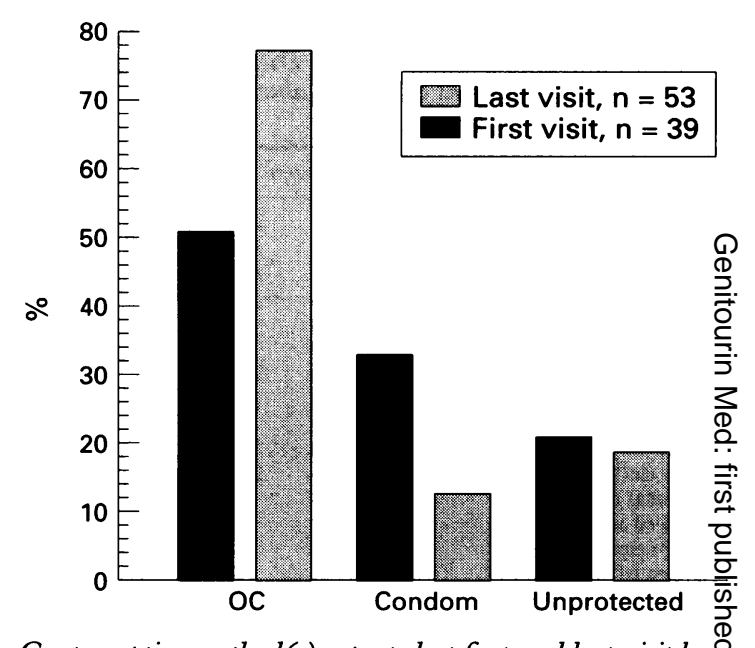

Contraceptive method(s) reported at first and last visit by those reporting coitus the last month (OC = oral contraceptive). More girls were using condoms prior to the first visit compared with the last visit $(p<0.05)$ while more girls were using $O C$ at the last visit compared with the first visit $(p<0.05)$.

partners did not affect the distribution of answers. Monogamy was only mentioned bis $8 \%$ as protection against STD.

At the final visit (at 18 years of age) only $\frac{\circ}{4}$ girls $(6 \%)$ reported a latest coitus with $O \vec{G}$ supplemented by a condom. Of 10 girls reporting use of a condom the last month, also admitted unprotected coitus during the month. Nineteen girls $(27 \%)$ reported a first unprotected coitus and $7(10 \%)$ a latest unprotected one. Change of contraceptive method was most common among girl reporting use of condom at 16 . Thirteen of 1 증

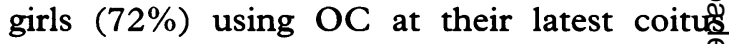
before the first visit also used OC at their most recent coitus before the last visit. However, of 21 girls $(19 \%)$ using condom at their firs visit were still condom users at the last visit ( $\mathrm{p}$ 0.001 ). Three of 5 girls who ceased to use O reported a latest unprotected coitus. Side. effects or fears were given as reasons for inters rupting OC use. Reasons for giving up con̄ dom use were: current OC use by 8 , stead partner by 5 and discomfort by 4 girls, 2 of whom used no contraception at all.

\section{Discussion}

All the girls who were invited to participate if this study were of uniform age and had comot menced their upper secondary school educa tion in the health care programme course Participation in the study meant a rather subo stantial undertaking. Fifty-eight per cent of the girls accepted the invitation. In order tes respect the integrity of the girls refusing to pard ticipate, we did not investigate this group Thus the studied group represents in some respects a selected group of the total popula tion of girls. The girls were all but one raised outside big cities. Sexually active girls may be over-represented in this study, as contracep? tive counselling was offered by the investigator. However, the studied sample represents approximately $15 \%$ of the total population of girls of this age resident in Karlstad at the time of this study and the distribution of social class 
showed little differences from the equivalent national distribution. ${ }^{17}$

The girls were well-informed as Swedish teenagers usually are. ${ }^{7-10}$ There were only minor differences in knowledge and behaviour between girls from different socioeconomic groups. The girls had the highest level of knowledge regarding chlamydia and least knowledge about genital herpes at both 16 and 18 years of age. None of the girls included in this study had experienced a gonorrhoea or genital herpes infection. Gonorrhoea is today an uncommon disease in Sweden which may explain the lower level of knowledge concerning gonorrhoea among girls. The girls knowledge concerning genital herpes was low indicating the need for more information. One half of the girls thought they were insufficiently informed about STDs. There was an improvement in knowledge regarding chlamydia, condyloma and gonorrhoea between 16 and 18 years of age. It is possible that their knowledge further increased during the study dependent on their special type of education, and even participation in this study may have contributed to better information. Our purpose, however, was not to instruct the girls, only to give them advice if they enquired.

Chlamydia trachomatis infection is today the most important bacterially transmitted STD in Sweden. In the early eighties $20 \%$ of teenagers attending youth clinics had chlamydia. The prevalence of chlamydia today is estimated to be less than $5 \%$. This reduction has been achieved by a combination of measures such as educational efforts directed towards health care staff and young people, screening programmes and treatment policies including partner tracing. ${ }^{18}$ In this study HPV infection was the most common STD. Our study provides some evidence for the conclusion that screening programmes and treatment policies including partner tracing have been the most effective measures in reducing the occurrence of chlamydia infections. The hypothesis is substantiated by the fact that although girls were well-informed about sexually transmitted diseases and knew how to avoid infections this knowledge had little influence on behaviour.

The girls in this study did not appear to differ from those in earlier Swedish studies regarding the number of coital partners. Weiner et $a l^{19}$ and Klanger et $a l^{20}$ reported that $30-40 \%$ of sexually experienced 17 year old girls in a Swedish city had had more than two partners. We found that 32 of $71(45 \%) 18$ year old girls, had had more than two sexual partners, and $20(28 \%)$ more than four partners. These 20 girls were best informed, but in spite of solid knowledge they did not protect themselves better from infection. Consequently they were at higher risk of being subjected to an STD. The possibility of transmission of an STD at their latest coitus was denied by almost all girls. This is in agreement with a Canadian study where most sexually active students, "whether monogamous, promiscuous, or average", believed their partners could not possibly be infected. ${ }^{21}$ Psychological characteristics of adolescence such as denial and feelings of invulnerability may explain this opinion. ${ }^{12} 13$ The frequent occurrence of asymptomatic infections may further encourage this form of behaviour.

The distribution of contraceptive methods is in agreement with what Brännström et $a l^{2}$ found in the same period in a comparable Swedish population. The opportunity to obtain contraceptive counselling by the investigator may have increased the use of $\mathrm{OC}$; many had tried the method but in some cases only for a short period. The great majority had experience of condoms. Our data showed a significant reduction in condom use with rising age and an increased use of OC, which is in agreement with observations among Norwegian adolescents. ${ }^{23}$ Brännström et $a l^{22}$ showed that teenagers mostly used condoms for less than one year. Condoms were used primarily for birth control but seldom in order to avoid infections although all girls proposed the condom as the best method for STD protection. The frequency of recent condom use does not necessarily reflect consistency of use. ${ }^{23}$ Of 10 girls reporting use of a condom last month, 3 admitted unprotected coitus during this month. When condom was adopted it was, however, most often used during the whole coitus. Change of methods was common but no consideration was seen regarding STD protection. The condom was not favoured in connection with partner change. When interrupting one method as a result of dissatisfaction, totally unprotected coitus was a common result.

Five years ago many students thought the intention to keep to one partner was sufficient as STD protection. ${ }^{7}$ In the present study everyone mentioned the condom as the STD protection method of choice and only $8 \%$ named monogamy. This would possibly be a more realistic opinion because infections persist for long periods and most teenagers live in what has been called "serial monogamy". This study indicates, however, that theoretical knowledge does not influence actual behaviour.

This longitudinal study has shown good and increasing knowledge about STD, paradoxically accompanied by unsatisfactory STD protection. The process of decision-making related to sexual behaviour and contraceptive choice, was not only affected by knowledge but probably also by complex psychological, developmental and social factors. The risktaking behaviour, in spite of good factual knowledge, observed in this study as well as in other studies is poorly understood. Recent studies support the important role of perceived peer norms in influencing consistent condom use among adolescents. ${ }^{124}$ As in other studies, ${ }^{711}$ friends were the most common person for a discussion about these matters and individual reading the best source of information. Education by peers may provide one possible approach to the problem.

This work was supported by grants from the Centre for Public Health Research, Karlstad, Hjalmar Svensson's Fund and the University of Göteborg. 
1 Weström L. Incidence, prevalence and trends of acute pelvic inflammatory disease and its consequences in industrialized countries. Am F Obstet Gynecol 1980;138: 880-92.

2 Greenberg J, Magder L, Aral S. Age at first coitus. A marker for risky sexual behavior in women. Sex Transm marker for risky sex

3 Bosch FX, Munoz N, DeSanjosè I, et al. Risk factors for cervical cancer in Colombia and Spain. Int $\mathcal{f}$ Cancer 1992;52:750-8.

4 Lidegaard $\mathrm{O}$, Helm P. Pelvic inflammatory disease: the influence of contraceptive, sexual and social life events. Contraception 1990;41:475-83.

5 Miettinen A, Heinonen PH, Teisala K, et al. Serologic evidence for the role of Chlamydia trachomatis, Neisseria gonorrhoeae and Mycoplasma hominis in the etiology of tubal factor infertility and ectopic pregnancy. Sex Transm Dis 1990;17:10-4.

6 Zur Hausen H. Intracellular surveillance of persisting viral infections. Human genital cancer results from deficient cellular control of papilloma virus gene expression. Lancet 1986;ii:489-91

7 Andersson-Ellström A, Forssman L. Sexually transmitted diseases-Knowledge and attitudes among young people. 于 Adolesc Health 1991;12:72-6.

8 Persson E, Sandström B, Jarlbro G. Sources of information, experiences and opinions on sexuality, contraception and STD protection among young Swedish students. Advances in Contraception 1992;8:41-9.

9 Persson E, Jarlbro G. Sexual behaviour among youth clinic visitors in Sweden: knowledge and experiences in an HIV perspective. Genitourin Med 1992;68:26-31.

10 Tydèn T, Norden L, Ruusuvaara L. Swedish adolescent's knowledge of sexually transmitted diseases and their attitudes to the condom. Midwifery 1991;7:25-30.

11 Tydèn T, Björkelund C, Olsson S-E. Sexual behavior and sexually transmitted diseases among Swedish university students. Acta Obstet Gynecol Scand 1991;70:219-24.

12 Biro FM, Rosenthal SL. Psychological sequelae of sexually transmitted diseases in adolescents. Obstet Gynecol Clin N Am 1991;219:209-18.

13 Elkind D. Understanding the young adolescent. Adolescence 1978;13:127-34.

14 Nadelsson CC, Notman MT, Gillon JW. Sexual knowledge and attitudes of adolescents: Relationship to contraceptive use. Obstet Gynecol 1980;55:340-5.

15 Kegeles SM, Adler NE, Irwin CE. Adolescents and condoms. Associations of beliefs with intentions to use. AfDC 1989;143:911-5.

16 Statistics Sweden. Swedish socioeconomic classification. Reports on Statistical Co-ordination 1982;4:ISSN 0082-0029.

17 Statistics Sweden: Statistical Abstract of Sweden 1991 vol 77, Norstedts tryckeri, Stockholm 1990.

18 Persson E. The sexual behaviour of young people. $\mathrm{Br} f$ Obstet Gynaecol 1993;100:1074-6.

19 Weiner E, Johansson I, Helmius G. Sexual and contraceptive experience among teenagers in Uppsala. Upsala $\mathcal{F}$

20 Klanger B, Tydèn T, Ruusuvaara L. Sexual Behavior among adolescents in Uppsala, Sweden. $\mathcal{F}$ Adolesc Health 1993;14:468-74.

21 Netting NS. Sexuality in youth culture: Identity and change. Adolescence 1992;27:961-76.

22 Brännström M, Josefsson G-B, Liljestrand J. Contraception and sexuality in an area-specific group of Swedish women 15-34 years of age. Contraception 1991;44:445-52.

23 Traeen B. Norwegian adolescents sexuality in the era of Aids. Acta Obstet Gynecol Scand 1994;73:439-40.

24 Brown I DiClemente RJ, Park T. Predictors of condom use in sexually active adolescents. $\mathcal{F}$ Adolesc Health 1992; 13:651-7. 